\title{
Economic Risks of Aflatoxin Contamination in Marketing of Peanut in Benin
}

\author{
C. Bley N'dede, ${ }^{1}$ C. M. Jolly, ${ }^{1}$ Simplice D. Vodouhe, ${ }^{2}$ and P. E. Jolly ${ }^{3}$ \\ ${ }^{1}$ Department of Agricultural Economics and Rural Sociology, Alabama Agricultural Experiment Station, \\ Auburn University, Auburn, AL, USA \\ ${ }^{2}$ Department of Economics, Socio-Anthropology and Communication, University of Abomey-Calavi, Cotonou, Benin \\ ${ }^{3}$ Department of Epidemiology and International Health, University of Alabama at Birmingham, Birmingham, AL, USA
}

Correspondence should be addressed to C. M. Jolly, cjolly@auburn.edu

Received 20 June 2012; Accepted 31 July 2012

Academic Editor: Anthony N. Rezitis

Copyright (๑) 2012 C. Bley N'dede et al. This is an open access article distributed under the Creative Commons Attribution License, which permits unrestricted use, distribution, and reproduction in any medium, provided the original work is properly cited.

\begin{abstract}
Aflatoxin (AF) is a human health, nutrition, and financial risk to many people in the developing world. AF contamination in peanut is caused by the fungi: Aspergillus flavus and Aspergillus parasiticus. AF is a potent carcinogenic toxin that also causes millions of dollars of financial losses to people in Africa. The fungus producing the AF can be reduced to an acceptable level by proper drying, sorting, storage, and cleaning of peanut. Government intervention and regulation can also encourage market participants to reduce AF contamination. In this paper, we examine the financial risk associated with sorting, and storing of peanut and peanut products along the marketing chain. Study results show that the prices paid for peanut, prices received, the costs of sorting and storage are dominant factors in reducing AF levels in peanut. Practices such as drying, sorting, and storing, however, pose financial risks to market traders of peanut. Unless government intervenes by requesting an AF-reduced peanut and provides assistance for market liberalization where market participants consider quality in trading decisions, suppliers of peanut will be reluctant to adopt AFreducing techniques.
\end{abstract}

\section{Introduction}

Aflatoxins (AFs) are naturally occurring mycotoxins that are produced by species of fungus: Aspergillus flavus and Aspergillus parasiticus. AFs are some of the most potent toxic substances found in foods and feeds [1]. Numerous studies have also linked AFs to various diseases, such as cancer of the liver and hepatitis B and C. High levels of AF were detected in children with kwashiorkor in Sudan [2], in Durban, South Africa [3] and in Nigeria [4]. AFs are ubiquitous but are more commonly found in warm and humid climates and affect about one-quarter of the global food and feed crop output $[5,6]$. The fungi associated with AF production are found on peanut, maize, yams, cassava, and cereals that form the basic staples of the African diet. According to Cardwell et al. [7], AF contamination of agricultural crops causes annual losses of more than $\$ 750$ million in Africa. In the USA, it was reported that income losses due to AF contamination cost an average of more than US \$100 million per year to US producers [8]. According to FAO [9], developing countries account for approximately 95 percent $(\%)$ of world peanut production. Groundnut (or peanut) (Arachis hypogaea L.) is one of the most important crops in West Africa because it is not only a useful crop for rotation but also a cash crop.

Recent studies have linked AF contamination in foods to environmental conditions, poor processing, and lack of proper storage facilities in developing countries [10]. Contamination is usually most frequent and serious at the storage and processing level along the marketing chain. The AF contaminated peanut is tainted and cannot be marketed and must be thrown away. Awuah et al. [11] stated that about 5 to $15 \%$ of peanut in Ghana were discarded during sorting. Preand postharvest management strategies employed to reduce AF in food result in lower supply but better product quality.

In spite of the studies that have outlined the losses due to and the recommended practices to reduce the losses due to $\mathrm{AF}$, there is little written on the effects of AF on the financial returns of production and marketing of peanut. 
Hence, these questions must be raised. What are the financial and marketing risks associated to peanut $\mathrm{AF}$ contamination during postharvest handling in Benin? We examine the effects of AF contamination of peanut on the net revenues of market participants and the associated risks of adopting techniques to reduce AF levels in peanut marketed in Benin.

Benin is a West African nation with a hot and humid climate. About $70 \%$ of the economically active population is engaged in the agricultural sector. Food crops include cassava, yams, corn, sorghum, beans, rice, sweet potatoes, guavas, bananas, coconuts and peanut. Peanut is grown as a protein source and consumed throughout the country as part of the basic staple. All of the peanuts produced are marketed locally and are contaminated with varying levels of AF [12, 13]. AF levels acceptable by the World Health Organization (WHO) standard can be attained by proper postharvest handling. The post-harvest handling methods that are likely to have the greatest impact in reducing AF levels are drying, sorting and storage. However, each method employed for lowering AF levels is accompanied by additional costs to market participants. Processors and consumers may wish to avoid these costs based on their perception of the product's safety, the price, and the effects of lowering AF on their net revenues. To determine who will bear the cost can be explained by a simple microeconomic model.

Figure 1 represents a partial equilibrium model for peanut in which food regulation to improve food safety is observed, or suppliers voluntarily agree to improve the quality of peanut. The market demand $\left(D_{o}\right)$ and the supply $\left(S_{o}\right)$ curves determine the equilibrium price $\left(P_{E}\right)$ and quantity $\left(Q_{E}\right)$. In this market, farmers or market participants sort their peanut to improve quality. The sorting of peanut results in a reduction of the quantity supplied which forces the supply curve $\left(S_{o}\right)$ upward to the left to $S_{1}$. The demand curve $D_{o}$ remaining constant, the new price is $P_{1}$ and the new quantity is $Q_{1}$. The higher price $P_{1}$ is an indication that consumers perceive that the sorted nuts are of better quality, and hence they are willing to pay a higher price. However, if buyers perceive sorting of nuts as an indication that the peanuts are contaminated with AF, the demand curve $\left(D_{o}\right)$ may shift to the left $\left(D_{1}\right)$ resulting in a much lower price $P_{2}$ and quantity $Q_{2}$. Hence perceived lower quality results in a lower price and smaller quantity marketed.

Regulation requires pre- and postharvest control (appropriate drying sorting, and storage structures). If consumers are aware of AF problem and its market consequences, they will be willing to pay a higher price for a safer food supply. Thus, supply will shift to the left (Figure 1). Unnevehr [14] indicates that with consumers' awareness of a safer food product they are willing to buy more at a higher price. Mitchell [15] noted that consumers of milk in the USA purchased larger quantities of milk when they perceived the product as safe.

\subsection{Factors Affecting AF Contamination during Postharvest}

1.1.1. Drying. At harvest, moisture content in groundnut is generally high and leads to development of aflatoxigenic

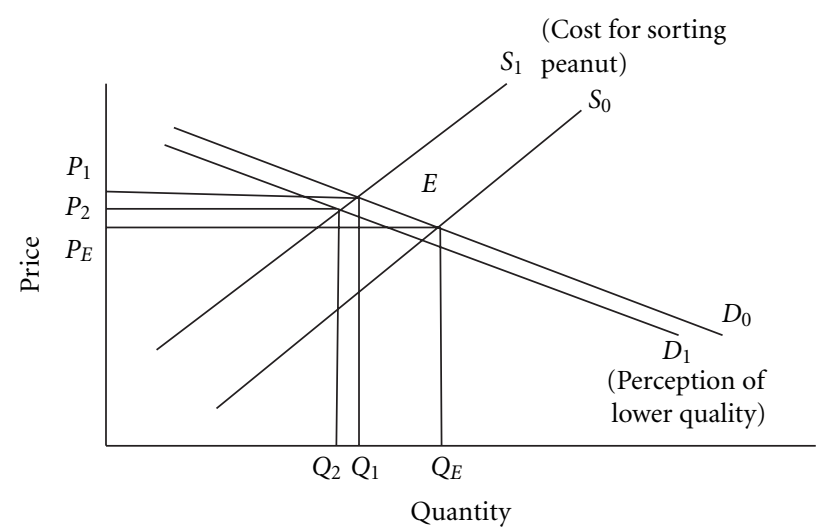

FIgURE 1: Market impact of food safety regulation.

fungi. It is recommended to dry peanut immediately down to $8 \%$ [16] in order to avoid production of AF during storage. In Benin, the most commonly used moisture reduction method for groundnut is sun drying. Farmers spread the nuts on the floor usually for one to three days. Paz et al. [17] reported that delayed drying can lead to a rapid increase in AF from $14.0 \mathrm{ppb}$ at harvest to $93.8 \mathrm{ppb}$, if maize is not dried for 5 days after the harvest. This was confirmed by Hell et al. [18] who found that postharvest contamination with AF in Benin increased when harvesting took more than 5 days and drying was delayed. Attah et al. [19] indicated that drying peanut to less than $10 \%$ moisture reduced $\mathrm{AF}$ contamination to the WHO acceptable level.

1.1.2. Storage. Another important postharvest factor affecting AF contamination is storage conditions. Grain crops may be attacked by fungi in the field which can then develop rapidly during storage when conditions are suitable for producing mycotoxins [20]. It is recommended that grain crops should be stored in a clean, sanitized room with low humidity and temperature and adequate air circulation. The relationship between the length of storage and the level of AF has been investigated [21].

1.1.3. Sorting. AF production is optimal in regions with high temperatures. Smallholder farmers in Benin use their own houses to store their product. The ambient temperature in Benin is about $81^{\circ} \mathrm{F}$. Contamination is more acute in warm, humid climate. In order to eliminate those with possible contamination, groundnut should be sorted before or after storage to remove defective or burrowed, contaminated grain. Awuah et al. [11] found that age, education, and gender influenced sorting of peanut. Women are more likely to sort peanut than men.

1.1.4. Food Policy on Groundnut. The risk of contamination by AFs is an important food safety concern for field crops [5]. In order to protect consumers from health risks, regulatory limits have been imposed on field crops intended for use as food and feed and have significant impact on the world export market. The WHO has set a maximum level for AF 
TABLe 1: Definition of parameters (inputs) used for risk models.

\begin{tabular}{|c|c|c|c|c|}
\hline Parameters & & Vendors & Processors & Stockers \\
\hline Price (selling) & $\$$ & Risk Triang $(0.09,0.11,0.13)$ & Risk Triang $(5,7,10)$ & Risk Triang $(0.63,1.05,1.5)$ \\
\hline Purchasing price & $\$$ & Risk Triang $(0.06,0.09,0.11)$ & Risk Triang $(0.1,0.15,0.2)$ & \\
\hline Purchase sorted peanut* & - & Risk Discrete $(\{0,1\},\{0.2,0.8\})$ & Risk Discrete $(\{0,1\},\{0.21,0.74\})$ & \\
\hline Sorting* No (0), Yes (1) & - & Risk Discrete $(\{0,1\},\{0.91,0.09\})$ & Risk Discrete $(\{0,1\},\{0.9,0.1\})$ & Risk Discrete $(\{0,1\},\{0.60,0.40\})$ \\
\hline Storage & - & Risk Triang $(0,4,8)$ & Risk Triang $(0,3,6)$ & Risk Triang $(0,3,7)$ \\
\hline Sorting costs & $\$$ & Risk Triang $(11,13.75,16.5)$ & Risk Triang $(0,60.5,120)$ & Risk Triang $(0.5,2,4)$ \\
\hline Bagging costs & $\$$ & Risk Triang $(4.5,6.88,9.5)$ & & \\
\hline Transportation cost & $\$$ & Risk Triang $(0.5,0.75,1)$ & & \\
\hline Shelling cost & $\$$ & Risk Triang $(26,28.13,30)$ & Risk Triang $(10,12.5,15)$ & \\
\hline Winnowing cost (1) & $\$$ & & Risk Triang $(0,2.5,5)$ & \\
\hline Frying cost & $\$$ & & Risk Triang $(20,22.75,25.5)$ & \\
\hline Winnowing cost (2) & $\$$ & & Risk Triang $(0.5,1.8,3)$ & \\
\hline Sorting cost $(2)^{* *}$ & $\$$ & & Risk Triang $(2.5,5,7.5)$ & \\
\hline Milling cost & $\$$ & & Risk Triang $(27.5,30.25,33)$ & \\
\hline Conditionment cost & $\$$ & & Risk Triang $(32.5,35.25,38)$ & \\
\hline Treatment cost & $\$$ & & & Risk Triang $(0,2,4.5)$ \\
\hline Stocking cost & $\$$ & & & Risk Triang $(0,0.5,1.5)$ \\
\hline
\end{tabular}

at 20 parts per billion ( $\mathrm{ppb}$ ) in human food and $100 \mathrm{ppb}$ in animal feed. Likewise, the Food and Drug Administration sets a tolerance limit for groundnut at $15 \mathrm{ppb}$. The European Union has set stricter standards; any food products with a concentration of AF greater than $4 \mathrm{ppb}$ cannot be marketed [5].

We investigate the effects of AF on peanut net revenues by examining the use of postharvesting techniques of reducing AF levels. We also examine the key variables that affect cost of reducing AF levels and the risks associated with the application of each of the recommended techniques. Various scenarios were examined at the market vendor, processors and stockers' level to analyze the costs, returns, and risks related to the reduction of AF levels in peanut.

\section{Method}

2.1. Sample and Survey Questionnaires. Data for this study were collected through face to face survey administered to a total of 15 traders, 15 stockers, and 30 processors in each of the three ecological zones of Benin: Kandi (north), Savalou (southeast), and Abomey-Bohicon (south).

Market participants were identified through the assistance of agricultural officers in the Ministry of Food and Agriculture (MoFA) and through the help of personnel from the University of Abomey-Calavi, Benin. Market participants were individually interviewed on their crop handling, sorting, storage practices, and household revenues. Moreover, information on the economic and financial aspects of processing, storage, and marketing of peanut was also collected.
2.2. Data Analysis. Survey data were analyzed using SAS software package version 9.1. The survey results were used to develop enterprise budgets for selling, storing, and processing peanut.

Furthermore, @RISK software was needed to simulate the risk of AF contamination on market participants' net revenues from the storage, processing, and trading of peanut. A Monte Carlo simulation was used in the risk analysis, using 10,000 iterations. Parameters used for @RISK are defined in Table 1. Standardized coefficients of regressions were obtained to determine the factors that pose the greatest risk to market participants in the postharvest handling of peanut to reduce AF contamination. The standardized coefficient refers to how many standard deviations a dependent variable will change, per standard deviation increase in the predictor variable. Cumulative probability distribution of net present values (NPVs) for market participants was used to evaluate the level of risks associated with certain actions to reduce AF levels.

\section{Results}

3.1. Sociodemographics. Most of the market participants were above 36 years old (Table 2). Stockers and vendors represented $53.3 \%$ and $51.1 \%$ of individuals, respectively, between the age group of 36 to 55 years while processors comprised of $48.1 \%$. A large percentage (77.8\% vendors, $100.0 \%$ processors, and $64.4 \%$ stockers) of the market participants were female, and most had no formal education. A large number of processors and stockers had between 0 and 15 years of experience while vendors had $44.4 \%$ having between 
TABLE 2: Sociodemographics characteristics for vendors, processors, and stockers peanut, by region $(N=45)$.

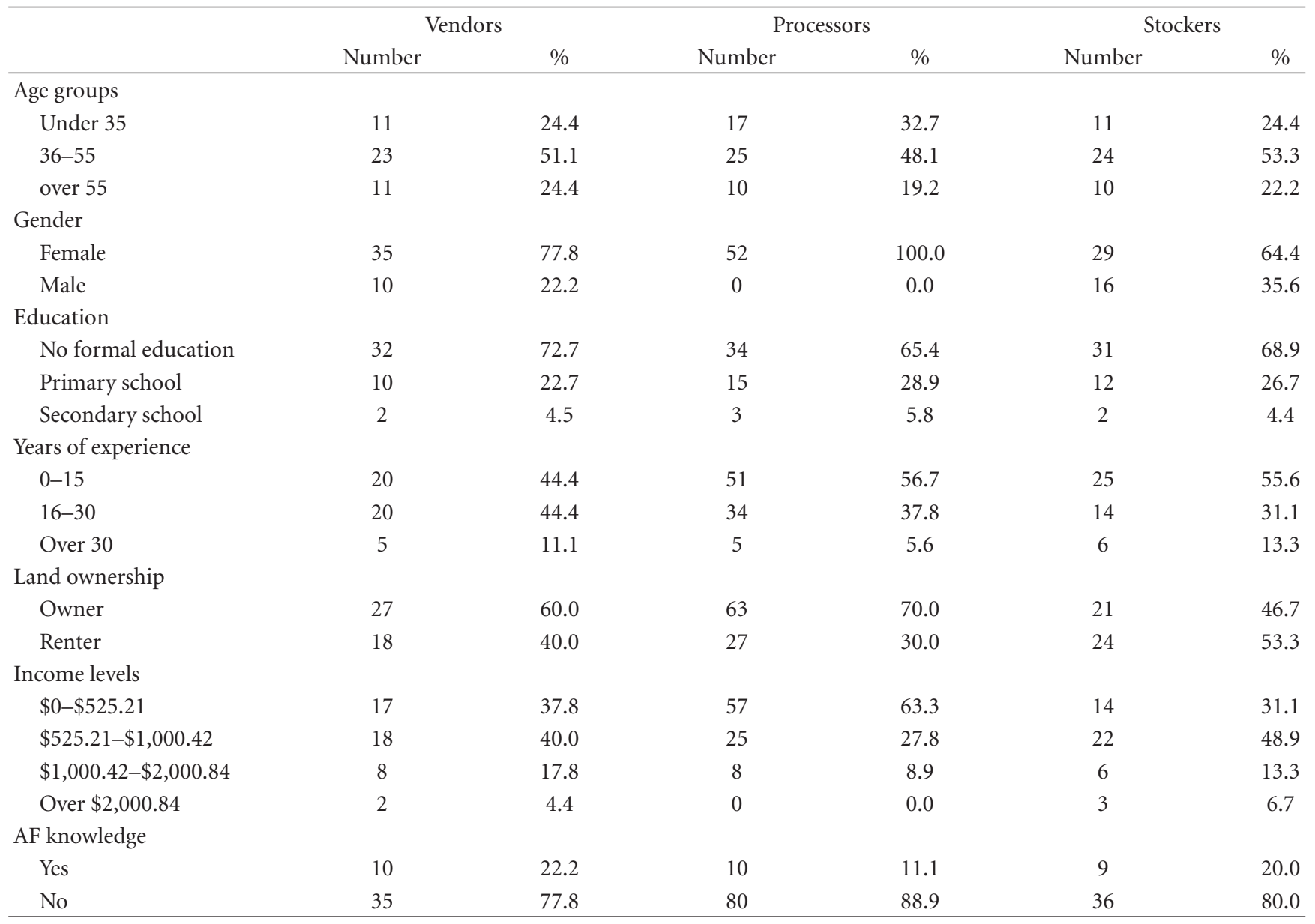

Source: survey data.

$N$ : the number of observations $(N=45)$.

Incomes for vendors are from sale of $5,500 \mathrm{~kg}$ of peanut.

Incomes for processors are from sale of $96 \mathrm{~kg}$ of peanut butter.

Incomes for stockers are $1,000 \mathrm{~kg}$ of peanut stored.

0 and 15 years. The incomes vendors received from peanut were modest, $77.8 \%$ having a lower income 1,000 CFA (US \$3.00) per $100 \mathrm{Kg}$ bag, while processors had 91.1\%, and stockers had $80.0 \%$. Most market participants had no knowledge of AFs. The percentage varied from $77.8 \%$ for vendors to $88.9 \%$ for processors.

\subsection{Storage and Sorting Practices}

3.2.1. Vendors. Based on survey responses, only retailers said that they are likely to sort peanut. Approximately, $80.0 \%$ of market vendors purchase sorted peanut and $20.0 \%$ do not purchase sorted peanut (Table 3). However, 91.1\% of vendors said that they always checked and sort the nuts before marketing. About $31.7 \%$ report that they sell the spoilt nuts at a lower price, and $68.3 \%$ state that they just discarded them.

3.2.2. Processors. About $74.4 \%$ of the processors surveyed stated that they purchased sorted peanut, while $21.1 \%$ do not purchase the sorted nuts and do not plan to do so in the future (Table 3 ). One reason given for buying sorted nuts was the expected price would be higher for sorted nuts and higher quality nuts generated quick sales. About $90 \%$ of them sort peanut before processing it into paste, oil, or other products, $7.78 \%$ do not sort the nuts before processing them but are willing and plan to do it in the future. Only $2.2 \%$ refused to sort before processing. In addition, of 81 respondents who sort peanut before processing, $41.9 \%$ reported that they discard the spoilt nuts, usually throw them away, burn them, or use them as charcoal. However, the remaining consumed them, used them as animal feed, or sell them at a lower price. About $89.5 \%$ of the processors mention that they usually store peanut for a period of 6 months.

3.2.3. Stockers. There is little difference in the decision made by the stockers to sort peanut. About $66.7 \%$ indicated that they always purchase sorted peanut, and only 33.3\% purchase nonsorted peanut. Among those who do not purchase sorted peanut, $80 \%$ intend to buy the cleaned nuts and only 
TABLE 3: Storage and sorting practices for each market participant.

\begin{tabular}{|c|c|c|c|c|c|c|}
\hline \multirow{2}{*}{ Decision } & \multicolumn{2}{|c|}{ Vendors } & \multicolumn{2}{|c|}{ Processors } & \multicolumn{2}{|c|}{ Stockers } \\
\hline & Number & $\%$ & Number & $\%$ & Number & $\%$ \\
\hline \multicolumn{7}{|l|}{ Purchase sorted peanut } \\
\hline Yes & 36 & 80.0 & 67 & 74.4 & 30 & 66.7 \\
\hline No & 9 & 20.0 & 19 & 21.1 & 15 & 33.3 \\
\hline \multicolumn{7}{|l|}{ Plan to purchase sorted peanut } \\
\hline Yes & 2 & 2.2 & - & - & 12 & 80.0 \\
\hline No & 7 & 77.8 & 19 & 100.0 & 3 & 20.0 \\
\hline \multicolumn{7}{|c|}{ Sort peanut before processing or marketing } \\
\hline Yes & 41 & 91.1 & 81 & 90.0 & 24 & 53.3 \\
\hline No & 4 & 8.9 & 9 & 10.0 & 21 & 46.7 \\
\hline \multicolumn{7}{|c|}{ Plan to sort peanut before processing or marketing } \\
\hline Yes & 2 & 50.0 & 7 & 77.8 & - & - \\
\hline No & 2 & 50.0 & 2 & 22.2 & - & - \\
\hline \multicolumn{7}{|l|}{ Discard spoiled or contaminated nuts } \\
\hline Just throw them away or burn & 28 & 68.3 & 34 & 41.9 & 15 & 62.5 \\
\hline Autoconsumption & - & - & 25 & 30.9 & - & - \\
\hline Animal feed & - & - & 13 & 16.1 & 9 & 37.5 \\
\hline Sell for a lower price or other & 13 & 31.7 & 9 & 11.1 & - & - \\
\hline
\end{tabular}

Answers were given by stockers who, besides storing, also produce, sell, and/or transform peanut.

$20 \%$ are not likely to do it. About $53 \%$ of peanut stockers, who state that they sort peanut before selling, are those who also produce, sell, and/or process peanut. The remaining $(46.7 \%)$ only specializes in storing products. However, for those who sort peanut before marketing, about $62.5 \%$ throw away or burn the spoiled grains, and $37.5 \%$ feed their animals with the rejected nuts.

\subsection{Financial Analysis of Effects of AF on Peanut}

3.3.1. Enterprise Budgets for Market Vendors. Budgets for market vendors in Benin are presented in Table 4 based on the assumption that consumers consider all nuts the same and pay the same price. The first budget concerns vendors who purchase nonsorted peanut and do not sort before selling; the second budget shows costs and net returns for those who purchase nonsorted peanut, but sort it before selling. In the third case, they purchase sorted peanut at a higher price and they do not sort again before selling. The assumption in this case is that market vendors are aware of peanut quality and the risk of consuming contaminated peanut and are willing to pay a higher price for improved food safety.

Table 4 displays the estimated costs and returns for market vendors who sell only unshelled peanut (wholesalers) and those who sell only shelled peanut (retailers). Comparing results from budgets 1 and 2 , it is observed that vendor's revenue for 52.25 bags of $100 \mathrm{~kg}$ of peanut decreases when they decide to sort peanut. Since the costs of sorting are transferred from farmers to vendors, labor costs for traders increase by $\$ 13.00$, resulting in higher variable costs (\$626.00), and consequently, smaller net returns of $\$ 155.70$. It is, therefore, less profitable for vendors who purchase nonsorted nuts to use their own labor to sort the peanut. The third case, in Table 4, shows a budget where the decision makers (wholesaler) purchase already-sorted peanut at a higher price and decide to sort again. Vendors receive lower net returns than in the last case because they pay a higher price for the product and incur additional costs for sorting. Higher purchasing price for clean peanut leads to an estimated loss of net returns of $\$ 62.30$.

Results are similar for retailers; it is not profitable in terms of net revenue to sort peanut before selling. Gross revenue for $4,500 \mathrm{~kg}$ decreases from $\$ 756.00$ to $\$ 726.80$ when sorting takes place. In addition, the purchase of a better quality product at a higher price results also in smaller net returns of $\$ 118.10$. Break even prices range from $\$ 0.11$ to $\$ 0.13$ for the wholesalers and $\$ 0.12$ to $\$ 0.14$ for the retailers.

3.3.2. Enterprise Budgets for Processors. Results from enterprise budgets for processing peanut are shown in Table 5. Fol-lowing the assumptions that $\mathrm{AF}$ increases with storage time, costs and returns for nonsorted peanut are compared to the costs and returns generated by processors who sort peanut stored for 3 months and for 6 months. Processors who do not sort peanut generate higher revenues (\$705.60) and net returns $(\$ 236.14)$. When the sorted peanut was stored for a period greater than or equal to 3 months, labor costs increased (\$174.58), generating lower net returns of $\$ 168.58$. Because of peanut's lower quality after 6 months of storage, processors have to throw away $5 \%$ of the peanut which results in lower net returns (\$147.42).

Hence, to compensate for the loss due to sorting, we assume that a change in price is accompanied by sorting stored peanut for various time periods. It is observed that net 
TABLE 4: Estimated costs and returns budget for vendors (wholesalers) under the following assumptions. (1) Vendors purchased nonsorted peanut and do no sort before marketing. (2) Vendors purchased nonsorted peanut and sort before marketing. (3) Vendors purchased sorted peanut at a higher price and do not sort before marketing.

\begin{tabular}{|c|c|c|c|c|c|c|c|}
\hline & \multirow{3}{*}{ Unit } & \multicolumn{3}{|c|}{ Wholesalers } & \multicolumn{3}{|c|}{ Retailers } \\
\hline & & (1) & $(2)$ & (3) & (1) & (2) & (3) \\
\hline & & Value & Value & Value & Value & Value & Value \\
\hline Unshelled peanut & $\mathrm{kg}$ & 5,500 & 5,225 & 5,500 & 4,500 & 4,275 & 4,500 \\
\hline Price & $\$$ & 0.147 & 0.15 & 0.15 & 0.168 & 0.17 & 0.17 \\
\hline Revenue & $\$$ & 808.5 & 783.8 & 825.0 & 756.0 & 726.8 & 765.0 \\
\hline \multicolumn{8}{|l|}{ Variable costs } \\
\hline Quantity purchased & $\mathrm{kg}$ & 5,500 & 5,500 & 5,500 & 4,500 & 4,500 & 4,500 \\
\hline Price & $\$$ & 0.105 & 0.105 & $\$ 0.126$ & 0.11 & 0.11 & 0.13 \\
\hline Purchasing costs & $\$$ & 577.5 & 577.5 & $\$ 693.0$ & 495.0 & 495.0 & 585.0 \\
\hline Labor hour & hour & 28.5 & 54.0 & 28.5 & 68.5 & 87.0 & 68.5 \\
\hline Labor costs & $\$$ & 7.63 & 20.63 & 7.63 & 34.5 & 43.75 & 34.5 \\
\hline Material and equipment & $\$$ & 28.89 & 27.84 & 28.89 & 23.63 & 22.58 & 23.63 \\
\hline Total variable costs & $\$$ & 614.0 & 626.0 & 729.5 & 553.1 & 561.3 & 643.1 \\
\hline Income above variable costs & $\$$ & 194.48 & 157.8 & 95.5 & 202.9 & 165.4 & 121.9 \\
\hline \multicolumn{8}{|l|}{ Fixed costs } \\
\hline Repair and maintenance & $\$$ & 1.0 & 1.0 & 1.0 & 2.5 & 2.5 & 2.5 \\
\hline Depreciation equipment & $\$$ & 1.13 & 1.13 & 1.13 & 1.23 & 1.21 & 1.23 \\
\hline Total fixed costs & $\$$ & 2.13 & 2.13 & 2.13 & 3.73 & 3.71 & 3.73 \\
\hline Total costs & $\$$ & 616.2 & 628.1 & 731.7 & 556.9 & 565.0 & 646.9 \\
\hline Net returns & $\$$ & 192.4 & 155.7 & 93.4 & 199.1 & 161.7 & 118.1 \\
\hline \multicolumn{8}{|l|}{ Break-even price (per kg sold) } \\
\hline To cover variable expenses & $\$$ & 0.111 & 0.12 & 0.133 & 0.118 & 0.126 & 0.139 \\
\hline To cover total expenses & $\$$ & 0.112 & 0.12 & 0.133 & 0.119 & 0.127 & 0.14 \\
\hline
\end{tabular}

Peanut is sold to vendors at the farm gate price, which is 50 FCFA per $\mathrm{kg}(\$ 0.105)$.

Wholesalers are vendors selling unshelled peanut in local and neighbors' villages at 70 FCFA (\$0.147) per kg.

Retailers are vendors who sell only shelled nuts; price of shelled peanut is higher than the unshelled nuts: 80 FCFA ( $\$ 0.168$ ) per kg.

In the third case (3), the purchased cost of $1 \mathrm{~kg}$ of peanut already sorted is $60 \mathrm{FCFA}=\$ 0.126$.

Material and equipment are considered as variable costs because they are renewed every year.

returns above all costs drop for processors who sort peanut 3 months after harvest $(\$ 137.38)$ and also for processors with peanut stored for more than 6 months $(\$ 116.22)$.

3.3.3. Enterprise Budgets for Stockers. Results are displayed in Table 6. Two types of storage practices are studied; traditional stockers are stockers who store peanut in banco buildings, on the floor, in plastic bags, on hay, or on the top of the roof of their house, while the improved storage facilities are built of bricks and have storage racks. Average income for peanut stockers using the traditional method is $\$ 735.00$ for $1,000 \mathrm{~kg}$ of stored peanut, at a total cost of $\$ 10.70$ and net returns of $\$ 724.30$. Stockers using the improved method, however, generate revenues of $\$ 1,051.00$ per month, total costs of $\$ 12.93$, and net returns of $\$ 1,038.07$. It was assumed that if owners of stored products (farmers or vendors) were asked to sort peanut after a given period of time, they would have to throw away a certain amount $(2-5 \%)$ of the product resulting from deterioration due to storage time; therefore, the amount they would have to pay would be smaller. This assumption is based on the investigation by Kaaya and Warren [22]. Results based on this assumption are also presented in Table 6. For less than 3 months of storage, revenue decreases to $\$ 720.30$ with the same variable costs (\$8.18) and reduced net returns of $\$ 709.60$. After 6 months of storage, traditional stockers' income lowers to $\$ 698.25$ (Table 6). Net returns are therefore reduced by $\$ 22.05$. We note that as peanut quality is lowered due to storage time, stockers' revenue is also reduced from $\$ 1,029.98$ to $\$ 998.45$, resulting in a decrease in net returns from $\$ 1017.35$ to $\$ 985.82$.

3.4. Risk Analysis for Market Vendors. Probability distribution for net returns for wholesalers who do not sort peanut is presented in Figure 2. Purchasing price is the most dominant variable in the regression. There is a positive relationship between selling price and net returns (0.55). This indicates that as selling price increases by one standard deviation, net returns for peanut wholesalers increase by 0.55 standard deviation. However, there is a negative relationship between net returns, purchasing price, and sorting. Coefficients are -0.753 and -0.228 , respectively. Figure 2 (b) shows similar results when market vendors purchased sorted peanut at a high price and sell it without further sorting. Purchasing price is the most important contributing variable in 
TABLE 5: Estimated costs and returns for processing peanut, using 2,400 kg of whole grain peanut per month, under the following assumptions. (i) Case 1: peanut is normally purchased at $\$ 0.15$ per kilogram and sold at $\$ 7.35$ a bassin of peanut butter. (ii) Case 2: peanut is purchased at different price due to storage length and sorting.

\begin{tabular}{|c|c|c|c|c|c|c|c|}
\hline & \multirow{4}{*}{ Unit } & \multicolumn{3}{|c|}{ Case 1} & \multicolumn{3}{|c|}{ Case 2} \\
\hline & & \multirow{3}{*}{$\begin{array}{c}\text { Not sorted } \\
\text { Value } \\
\end{array}$} & \multicolumn{2}{|c|}{ Sorted } & \multirow{3}{*}{$\begin{array}{c}\text { Not sorted } \\
\text { Value } \\
\end{array}$} & \multicolumn{2}{|c|}{ Sorted } \\
\hline & & & 3 months & 6 months & & 3 months & 6 months \\
\hline & & & Value & Value & & Value & Value \\
\hline Peanut butter (1 kg@ \$7.35) & $\mathrm{kg}$ & 96.00 & 95.04 & 92.16 & 96.00 & 95.04 & 92.16 \\
\hline Revenue & $\$$ & 705.60 & 698.54 & 677.38 & 705.60 & 698.54 & 677.38 \\
\hline Whole grains & $\mathrm{kg}$ & 2,400 & 2,400 & 2,400 & 2,400 & 2,400 & 2,400 \\
\hline Unshelled nuts price & $\$$ & $\underline{0.147}$ & $\underline{0.147}$ & $\underline{0.147}$ & $\underline{0.126}$ & $\underline{0.16}$ & $\underline{0.16}$ \\
\hline Purchasing costs & $\$$ & 352.8 & 352.8 & 352.8 & 302.4 & 384.0 & 384.0 \\
\hline Labor hours & hour & 186.0 & 258.0 & 258.0 & 186.0 & 258.0 & 258.0 \\
\hline Labor cost & $\$$ & 114.08 & 174.58 & 174.58 & 114.08 & 174.58 & 174.58 \\
\hline Material and equipment & $\$$ & 0.63 & 0.63 & 0.63 & 0.63 & 0.63 & 0.63 \\
\hline Total variable costs & $\$$ & 467.51 & 528.01 & 528.01 & 417.11 & 559.21 & 559.21 \\
\hline Income above variable costs & $\$$ & 238.09 & 170.53 & 149.37 & 288.49 & 139.33 & 118.17 \\
\hline Repair and maintenance & $\$$ & 1.00 & 1.00 & 1.00 & 1.00 & 1.00 & 1.00 \\
\hline Depreciation equipment & $\$$ & 0.95 & 0.95 & 0.95 & 0.95 & 0.95 & 0.95 \\
\hline Total fixed costs & $\$$ & 1.95 & 1.95 & 1.95 & 1.95 & 1.95 & 1.95 \\
\hline Total costs & $\$$ & 469.46 & 529.96 & 529.96 & 419.06 & 561.16 & 561.16 \\
\hline Net returns & $\$$ & 236.14 & 168.58 & 147.56 & 286.54 & 137.38 & 116.22 \\
\hline \multicolumn{8}{|l|}{ Break-even price (per kg sold) } \\
\hline To cover variable expenses & $\$$ & 4.87 & 5.56 & 5.73 & 4.50 & 5.93 & 5.18 \\
\hline To cover total expenses & $\$$ & 4.89 & 5.58 & 5.75 & 4.52 & 5.95 & 5.20 \\
\hline
\end{tabular}

Material and equipment are considered as variable costs because they are renewed every year.

TABLE 6: Estimated costs and returns for peanut storage activities under the following assumptions. (i) No treatment is done for stored peanut in the traditional storage method. (ii) Decision maker authorize customers (farmers, vendors, or processors) to sort peanut. (iii) Peanut is stored for less than 3 months and more than 6 months.

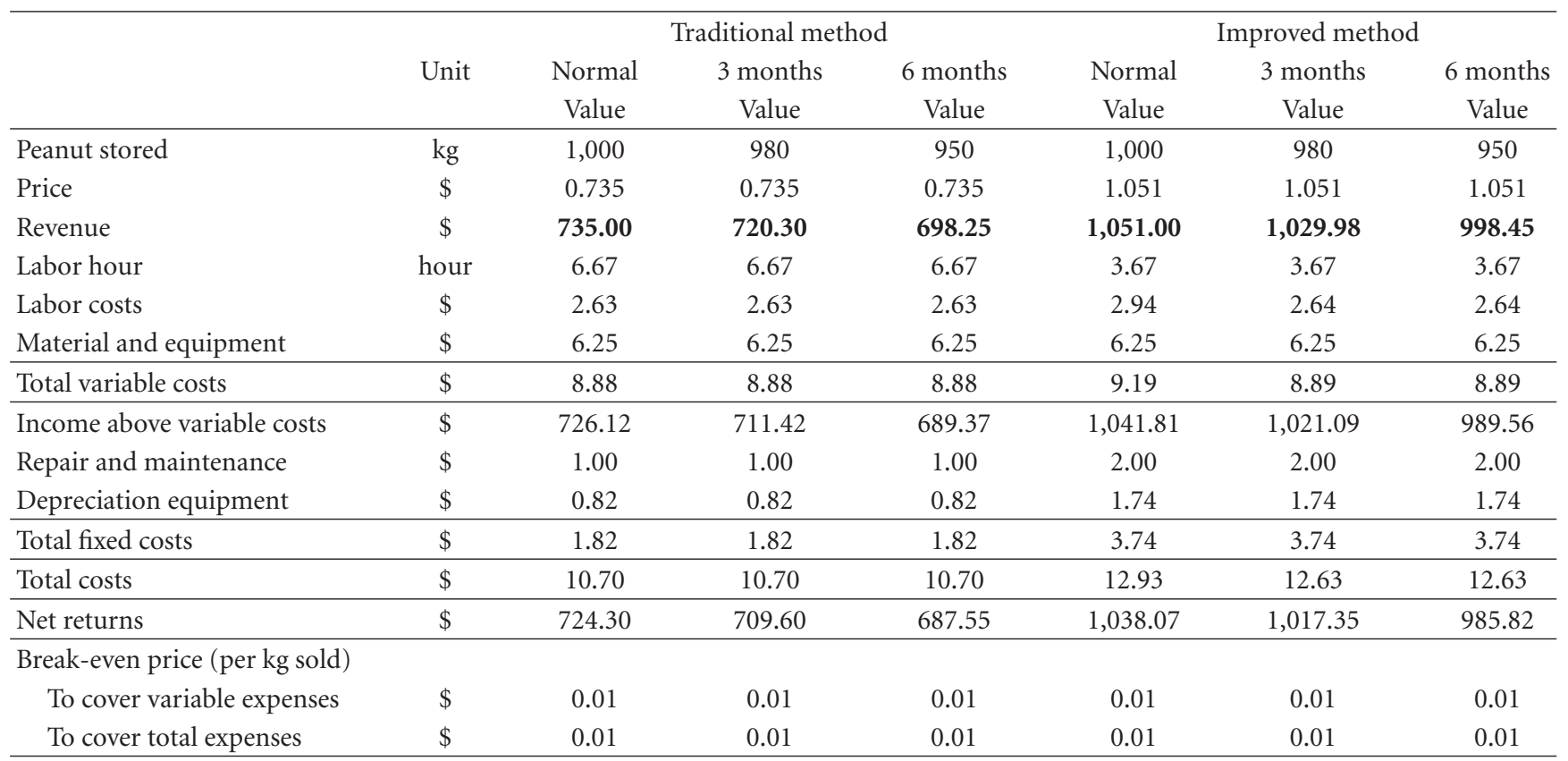

Percent of quantity rejected in $2 \%$ for peanut stored less than 3 months and $5 \%$ for peanut stored after six months. 


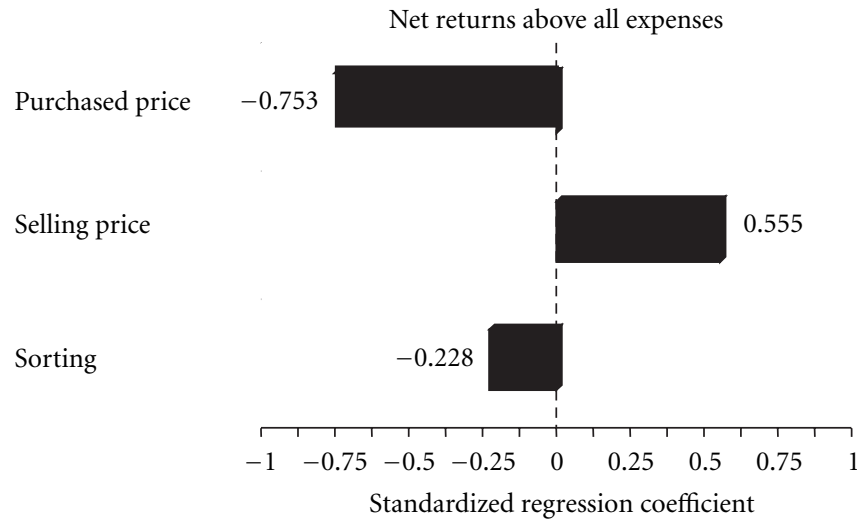

(a) Assumption: vendors purchase unsorted peanut and sort before marketing

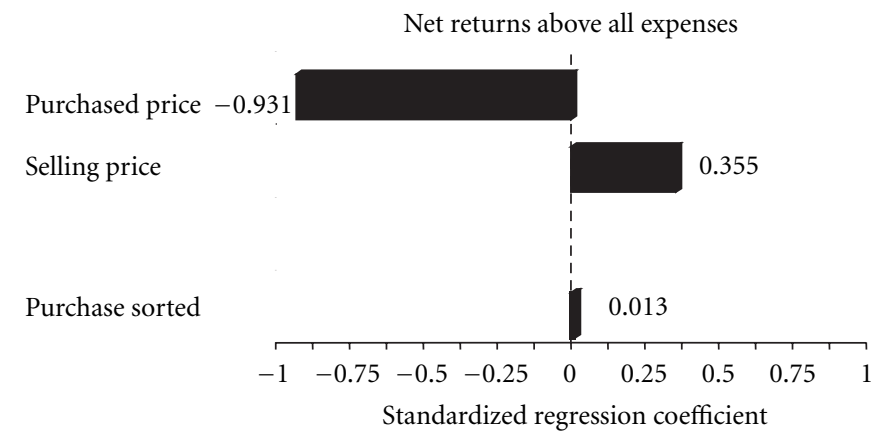

(b) Assumption: vendors purchase sorted peanut at a high and no sorting before marketing

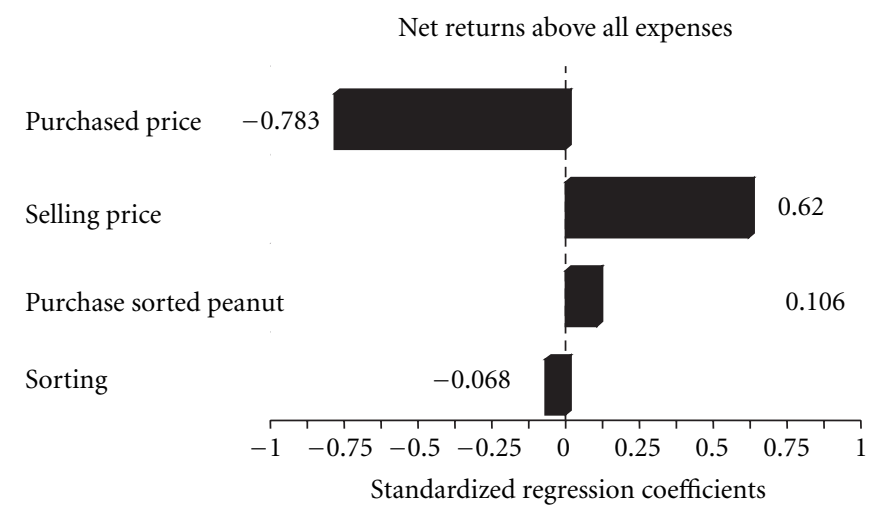

(c) Assumption: vendors purchase sorted peanut at a lower price (\$0.09) due to storage time, and they sort again for marketing

FIGURE 2: Tornado graphs of regression of net returns for peanut vendors in Benin.

the model. Purchasing already sorted peanut at a higher price causes net returns to decrease by 0.93 standard deviation. As selling price increases by one unit, net returns increase also by 0.355 . In addition, coefficient for the variable purchase sorted peanut is positive (0.013). By purchasing alreadysorted peanut, vendors avoid the cost of sorting which is shifted to the sellers. In Figure 2(c), assumptions are made on the effect of storage time on vendors' net returns. Assuming that vendors are aware of low peanut quality after a long storage period, they will purchase peanut at a lower price. Tornado graphs show that purchasing price is the most dominant variable $(-0.783)$ influencing traders' net returns. When the variable purchase price of sorted peanut increases by one standard deviation, net returns also go down by 0.783 ; results also show that the variable sorting $(-0.068)$ has a negative influence on vendors' net returns when they sort peanut to improve quality. The decision to buy clean nuts is made by the vendors. Moreover, there is a positive correlation between the variable purchase sorted peanut and net returns (coefficient $=0.106$ ).

A comparison of the net present value for different decision makers is made in Figure 3, based on assumptions used to generate previous budgets in Table 4. Vendors in option $\mathrm{A}$ are those who purchase unsorted peanut and do not sort again before selling; vendors in option B are those who purchase non-sorted peanut and sort before selling; vendors in option C; are those who purchase already-sorted peanut and do not sort the product again before selling. There is a risk transfer from buyers (vendors) to sellers when vendors purchase already sorted peanut.

No change in labor cost is noted for the vendors in options A and C. Figure 3 shows that there is a probability of $18 \%$ NPV for all options are less than zero and then become positive, but option $\mathrm{A}$ is less risky than option $\mathrm{C}$, and finally than option B. For all levels of discounted profits, option A would be considered the most efficient set and would be the most rational. In option A, the market vendor may use family members' labor to sort and enforce high-quality control.

3.5. Risk Analysis for Processors. Results from regression sensitivity analysis for net returns are shown in Figures 4(a), 4(b), and 4(c) for processors who do not sort peanut and who sort peanut for less than 3 months and more than 6 months. Selling price plays an important role in processors net returns; coefficients are 0.90 when peanut is not sorted, 0.84 for sorted peanut stored less than 3 months, and 0.91 for sorted peanut stored more than 6 months. However, when 


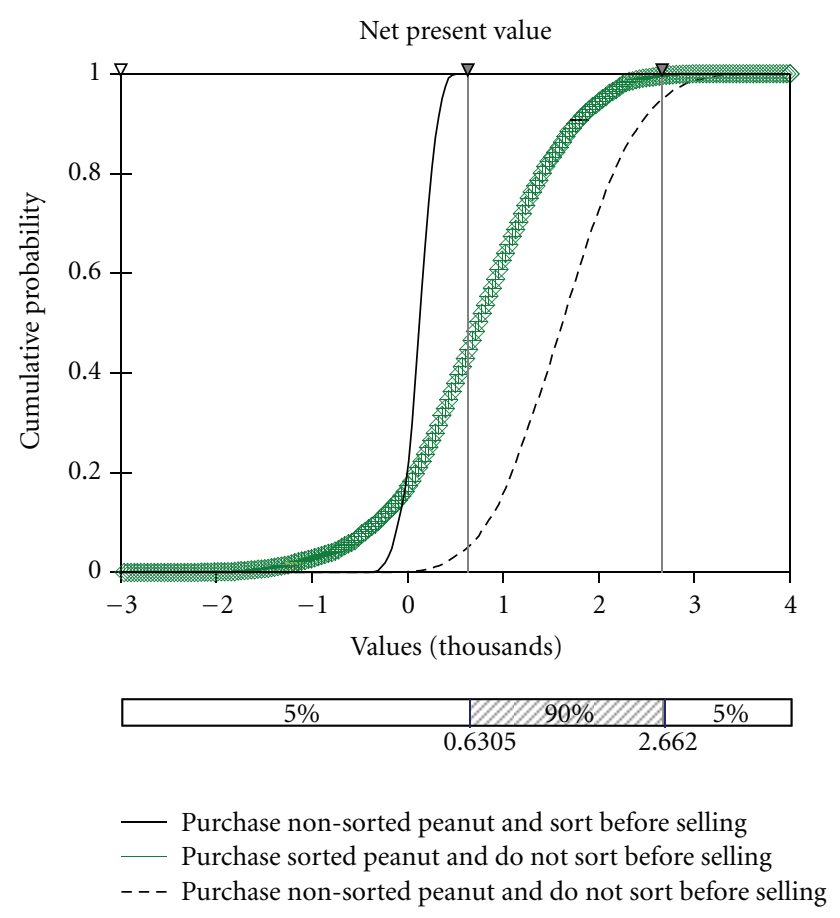

FIGURE 3: Cumulative probability distribution of net present values for vendors, discounted at $6 \%$ and using the assumptions shown in Table 4. (Assumptions: option A: vendors purchase unsorted peanut and do not sort before selling, option B: vendors purchase non-sorted peanut and sort before selling, option C: vendors purchase sorted peanut and do no sort again before selling.)

the decision makers are willing to sort peanut, there is a negative relationship between variables sorting $(-0.26$ and $-0.37)$, peanut purchasing price $(-0.46$ and -0.23$)$, storage $(-0.026$ and -0.028$)$, and shelling $(-0.001)$. Variables winnowing and sorting costs have a negative effect on processors net returns.

Cumulative distributions of the NPV for processors, as price vary due to sorting and storage, are presented in Figure 5. Processors who sort peanut and pay a higher price for sorted peanut stored for 3 months have a smaller NPV than the processors who do not sort peanut. With a probability of $20 \%$, NPV is equal to $\$ 600$ (Figure 5), which is smaller than the other options $(\$ 1,400)$. For some reason, the NPV curves for processors who sort peanut for a period less than 3 months and for those who sort peanut for a period greater than 6 months are close and almost at the same points. However, we can observe that it is more profitable for the same level of risk for processors to sort peanut stored for a period of less than 3 months.

3.6. Risk Analysis for Stockers. Tornado graphs in Figure 6 show the factors influencing net returns of each stocker. Price for storing is the most important variable in the regression model. Coefficient for price is 0.99 for both types of stockers indicating that, as price increases by $1 \%$, net returns will also increase by 0.99 standard deviation. In addition it is shown that net returns are negatively influenced by sorting $(-0.059)$ and storage $(-0.022)$.

Another comparison is made between stockers who use the traditional storage method and those who use the improved method for peanut conservation. Figure 7 shows that with a probability of $80 \%$, stockers who use treatment to improve peanut quality obtain a higher NPV (\$12.6) compared to those with a traditional storage method (\$8.4). Hence, we can conclude that for the same level of risk, stockers who use the improved method have a higher NPV than those using the traditional method.

\section{Discussion and Conclusion}

This study summarizes the results of the effects of AF contamination on the financial and economic risks during postharvest handling of peanut in Benin. Answers originating from surveyed market participants show that the majority of the respondents do not have any information on AF contamination of peanut and its harmful health effects to human and animals. Jolly et al. [23] also note similar responses for Ghanaian market participants. It also shows clearly that most of them are unable to identify AF contaminated nuts, but only signs of spoilage like discoloration or insect damage. Jolly et al. [24, 25] observed that the knowledge of AF was low among market participants in Ghana and Benin. Hence market participants must be educated to identify poor quality peanut if they are to sort in order to reduce AF levels.

The budget analysis shows that AF contamination lowers the net revenue of market participants since the tainted nuts were discarded in an effort to improve quality. The dominant factors influencing the revenues are purchase price and sorting. This is confirmed by the regression analysis. For market participants to participate in an AF reduction program, they would have to be given a price incentive for the sorting, labor cost increased and the rejection and discard of AF-contaminated nuts. Consumers should also be educated about the negative effects of AF so that they can encourage suppliers to sell a better product by offering a higher price for an AF-free product.

Enterprise budgets and risk analysis were developed and conducted to examine the risk of AF contamination on peanut marketing. When market participants sort peanut, total costs increase, resulting in lower net returns. Assuming that consumers consider all nuts the same and pay the same price, net returns for vendors who sort peanut before selling decrease by $\$ 36.7$ for $5,225 \mathrm{~kg}$ of nuts sold.

Risk analysis also confirms that it is more risky for market participants to either purchase already-sorted peanut before selling or purchase nonsorted and sort the nuts themselves before selling. A comparison made between costs and returns for peanut stored for less than 3 months and those from peanut stored more than 6 months indicates that net returns after 6 months are the smallest due to lowered peanut quality.

Budgets were developed for the processors to compare the costs and returns when they do not sort peanut and when they do at different storage times. Results show that sorting increases costs and risks of sorting peanut. Moreover, 


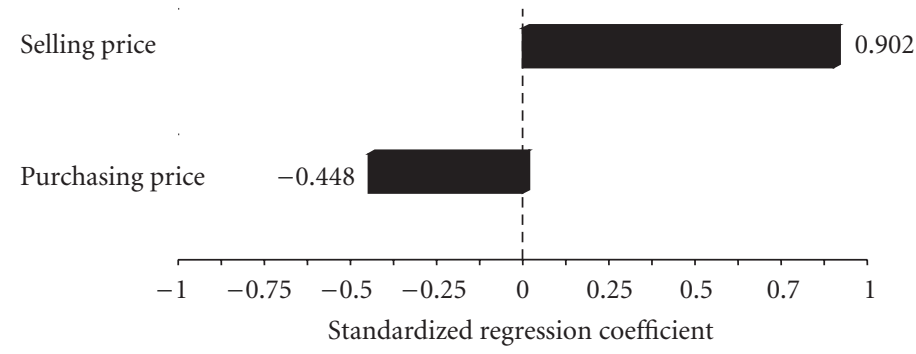

(a) No sorting

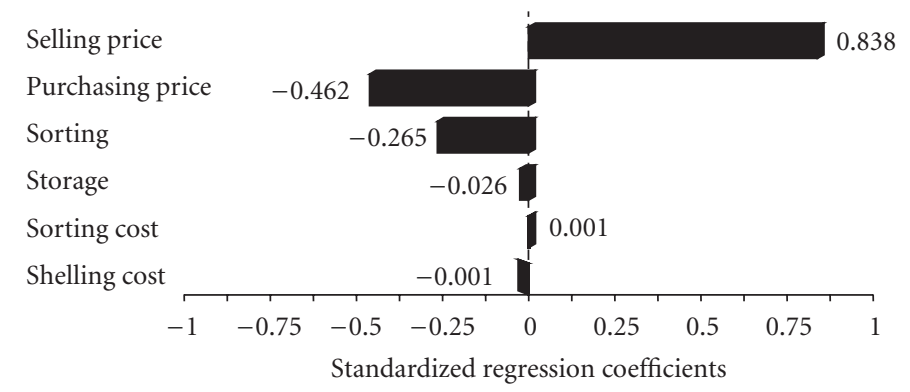

(b) Sorting of peanut stored for 3 months

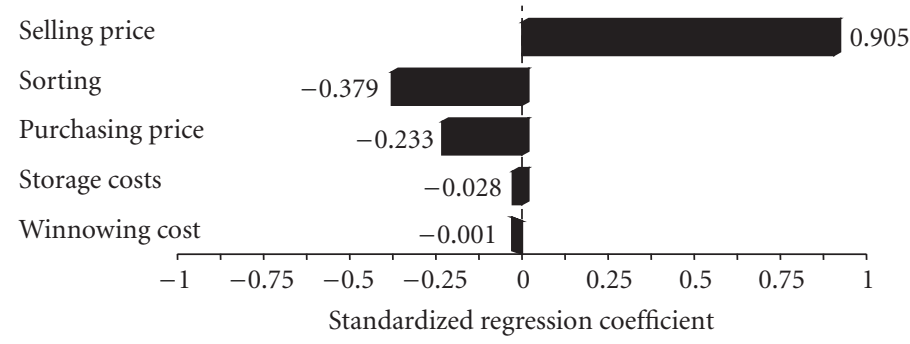

(c) Sorting of peanut stored more than 6 months

FIgURE 4: Tornado graphs for processors' net returns above all expenses, based on the budget in Table 5.

when sorting is done for a period of more than 6 months, net returns decrease further (\$147.42). Similar findings for stockers indicate that sorting peanut reduces net returns for storing $980 \mathrm{~kg}$ of peanuts from $\$ 1,038.07$ to $\$ 1,017.35$.

Sorting of nuts increases costs and lowers net returns. Market participants will be unwilling to sort peanut unless they receive a higher price for their product. Unless there is a policy in place for price increases for a better quality and safe product, market participants are likely to engage in cost shifting behaviors. Education is a key factor to increase market participants' willingness to sort peanut [11]. Jolly et al. [25] also emphasized increasing market participants' awareness of AF problem to encourage them to sort peanut.

Risk analysis for sorting shows it would be less risky if the buyer purchases the unsorted nuts and then sort the nuts himself/herself. Most peanut marketing enterprises in Benin have limited capital investment, and entrepreneurs use considerable amount of family labor to sort their nuts. This is concluded in the study by Awuah et al. [11] that young and older unemployed individuals are often engaged in sorting nuts. Hence, the labor cost is kept low and there is improvement in quality.
In conclusion, purchasing price negatively influences net returns and risks for all intermediaries. The decisions to sort by the market intermediary negatively influence net returns from sale. It is important that the purchaser does all in his/ her power to purchase clean nuts since the purchase of clean nuts positively influences his/her net returns.

For processors, selling price is the most dominant variable. Hence a processor must include in his/her promotion that the product is clean and safe and try to obtain the highest possible price that will positively influence his/her net returns. Therefore, sorted nuts should command a higher price.

For storage, cost of storage has the most important influence on net returns; however, decision to sort and length of storage negatively affects net returns.

Results from this study suggest that AF contamination of peanut is significantly influenced by drying, sorting, and storage. However, price of purchase, selling price, and costs of storage are significant contributors to business net revenues and unless government provides an economic incentive for producing quality peanut, suppliers will be hesitant to adopt measures to reduce AF levels. 


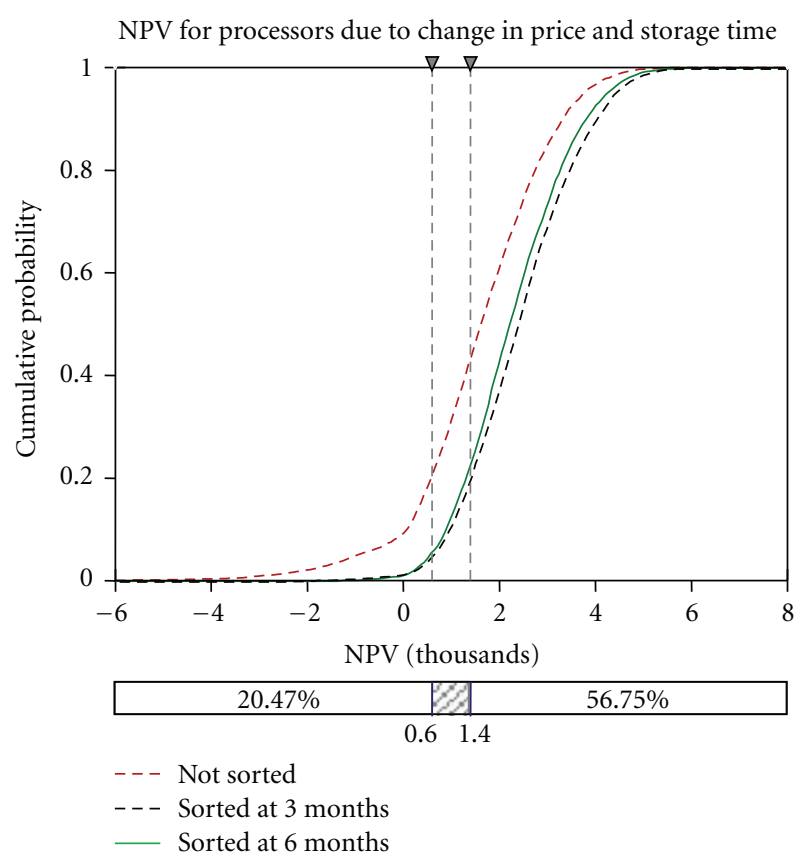

FIgURE 5: Cumulative probability distribution for the net present values of processors, as price changes due to sorting and storage time.

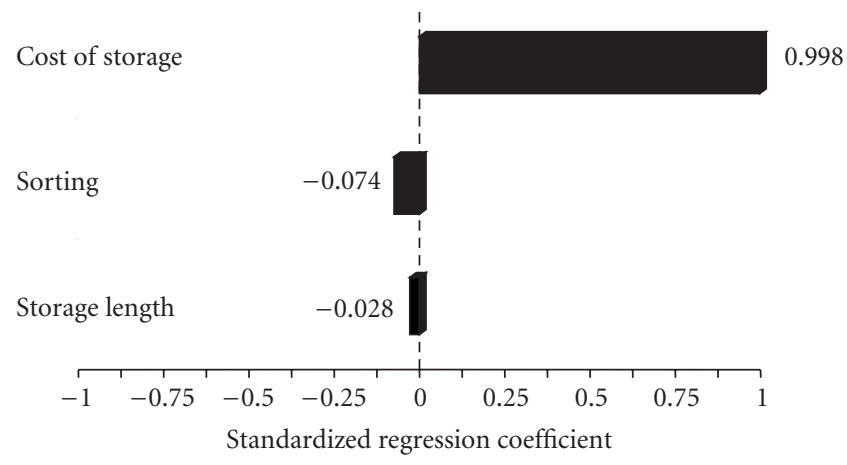

(a) Traditional method

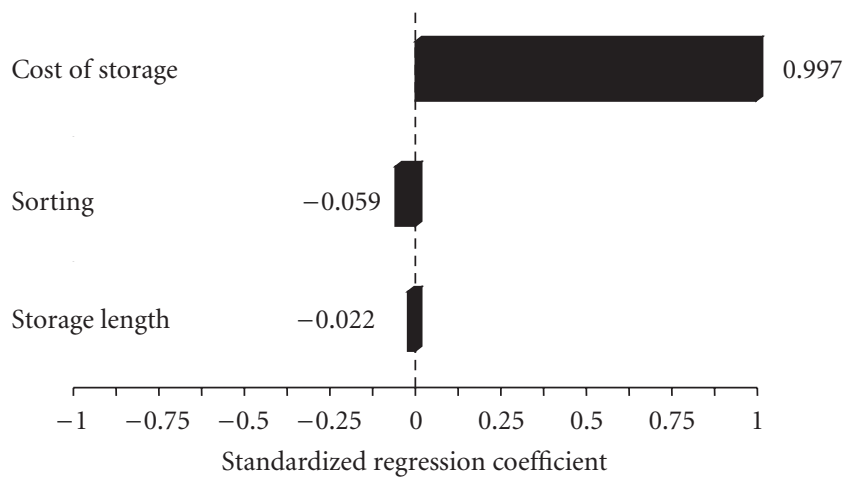

(b) Improved method

FIGURE 6: Tornado graphs for stockers' net returns.

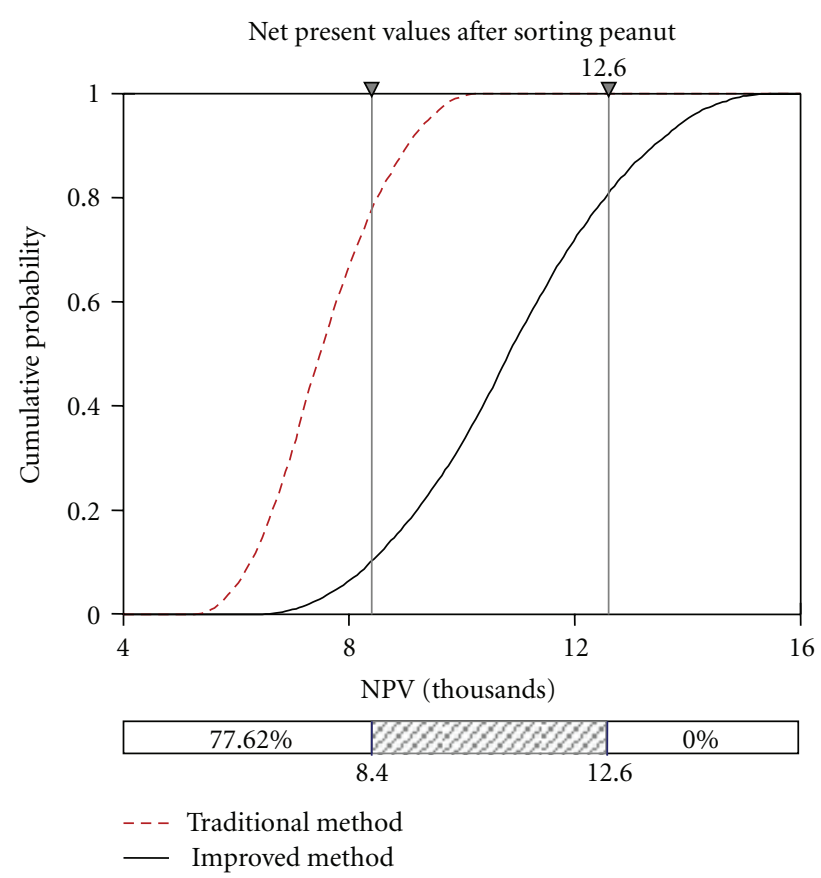

FIGURE 7: Cumulative probability distribution for the net present values for each method of storage when sorting is done.

Any measure to reduce peanut AF levels must be explained to the population of Benin so that they appreciate the course of action to be taken to reduce AF contamination in peanut.

\section{Acknowledgments}

This study was funded by the Peanut Collaborative Research Program, US AID Grant no. LAG-G-00-96-90013-00, and supported by Auburn University and The University of the Republic of Benin. The authors would like to thank the Ministry of Agriculture, Breeding and Fisheries of Benin for its support.

\section{References}

[1] D. K. Salunkhe, R. N. Adsule, J. K. Chavan, and S. S. Kadam, World Oilseeds: Chemistry, Technology, and Utilization, Springer, 1992.

[2] R. G. Hendrickse, J. B. Coulter, S. M. Lamplugh, S. B. Macfarlane, M. I. Omer, and G. I. Suliman, "Aflatoxins and kwashiorkor: a study in Sudanese children," British Medical Journal, vol. 285, no. 6345, pp. 843-846, 1982.

[3] G. Ramjee, P. Berjak, M. Adhikari, and M. F. Dutton, "Aflatoxins and kwashiorkor in Durban, South Africa," Annals of Tropical Paediatrics, vol. 12, no. 3, pp. 241-247, 1992.

[4] S. M. Lamplugh and R. G. Hendrickse, "Aflatoxins in the livers of children with kwashiorkor," Annals of Tropical Paediatrics, vol. 2, no. 3, pp. 101-104, 1982.

[5] E. Dohlman, "Mycotoxin hazards and regulations: impacts on food and animal feed crop trade," in International Trade and Food Safety: Economic Theory and Case Studies, J. Buzby, Ed., Agricultural Economic Report 828, USDA, ERS, 2003. 
[6] Food and Agriculture Organization (FAO), "Worldwide Regulations for Mycotoxins 1995: A compendium," FAO Food and Nutrition Paper No. 64, Rome, Italy, 1997.

[7] K. F. Cardwell, A. Desjardins, S. H. Henry, G. Munkyold, and J. Robens, The Costs of Achieving Food Security and Food Quality, 2004, http://www.apsnet.org/online/festure/mycotoxin/ top.html.

[8] O. Coulibaly, K. Hell, R. Bandyopadhyay, S. Hounkponou, and J. F. Leslie, Mycotoxins: Detection Methods, Management, Public Health and Agricultural Trade, CAB International, 2008.

[9] Food and Agriculture Organization (FAO), Food and Agricultural Statistics, Rome, Italy, 2002.

[10] E. O. Farombi, "Aflatoxin contamination of foods in developing countries: implications for hepatocellular carcinoma and chemopreventive strategies," African Journal of Biotechnology, vol. 5, no. 1, pp. 1-14, 2006.

[11] R. T. Awuah, S. C. Fialor, A. D. Binns, J. Kagochi, and C. M. Jolly, "Factors influencing market participants decision to sort groundnuts along the marketing chain in Ghana," Peanut Science, vol. 36, pp. 68-76, 2006.

[12] Y. Y. Gong, K. Cardwell, A. Hounsa et al., "Dietary aflatoxin exposure and impaired growth in young children from Benin and Togo: cross sectional study," British Medical Journal, vol. 325, no. 7354, pp. 20-21, 2002.

[13] K. Hell, K. F. Cardwell, and H. M. Poehling, "Relationship between management practices, fungal infection and aflatoxin for stored maize in Benin," Journal of Phytopathology, vol. 151, no. $11-12$, pp. 690-698, 2003.

[14] L. J. Unnevehr, "Food safety issues and fresh food product exports from LDCs," Agricultural Economics, vol. 23, no. 3, pp. 231-240, 2000.

[15] L. Mitchell, "Economic theory and conceptual relationships between food safety and international trade," in International Trade and Food Safety; AER \# 828, 2003.

[16] ICRISAT, "VIth International Conference on Legume Genentics and Genomics," Hyderbad, India, 2008.

[17] R. R. Paz, R. L. Tiongson, D. D. Dayanghirang, and A. C. Rodriguez, "Control of Aflatoxin in maize (Philippines) phase I," in Proceedings of the 12th ASEAN Seminar on Grain Postharvest Technology, pp. 4-8, ASEAN Grain Postharvest Programme, Surabaya, Indonesia, August 1989.

[18] K. Hell, K. F. Cardwell, M. Setamou, and H. M. Poehling, "The influence of storage practices on aflatoxin contamination in maize in four agroecological zones of Benin, West Africa," Journal of Stored Products Research, vol. 36, no. 4, pp. 365-382, 2000.

[19] A. Attah, R. T. Awuah, K. A. Kpodo, S. C. Fialor, and C. M. Jolly, "Cost effectiveness of selected post harvest pod handling techniques against damage, moldiness and aflatoxin contamination of shelled groundnut in Ghana," Journal of Science and Technology, vol. 27, no. 1, pp. 1-17, 2007.

[20] P. C. Turner, S. E. Moore, A. J. Hall, A. M. Prentice, and C. P. Wild, "Modification of immune function through exposure to dietary aflatoxin in Gambian children," Environmental Health Perspectives, vol. 111, no. 2, pp. 217-220, 2003.

[21] A. N. Kaaya and W. Kyamuhangire, "The effect of storage time and agroecological zone on mould incidence and aflatoxin contamination of maize from traders in Uganda," International Journal of Food Microbiology, vol. 110, no. 3, pp. 217223, 2006.

[22] A. N. Kaaya and H. L. Warren, "A review of past and present research on aflatoxin in Uganda," African Journal of Food Agriculture Nutrition and Development, vol. 5, no. 1, pp. 1-18, 2005.
[23] P. Jolly, Y. Jiang, W. O. Ellis et al., "Determinants of aflatoxin levels in Ghanaians: sociodemographic factors, knowledge of aflatoxin and food handling and consumption practices," International Journal of Hygiene and Environmental Health, vol. 209, no. 4, pp. 345-358, 2006.

[24] C. M. Jolly, B. Bayard, R. T. Awuah, S. C. Fialor, and J. T. Williams, "Examining the structure of awareness and perceptions of groundnut aflatoxin among Ghanaian health and agricultural professionals and its influence on their actions," Journal of Socio-Economics, vol. 38, no. 2, pp. 280-287, 2009.

[25] C. M. Jolly, B. Bayard, and S. Vodouhe, "Risks of ingestion of aflatoxin-contaminated groundnuts in Benin: scale measurements, beliefs, and socioeconomic factors," Risk Analysis, vol. 29, no. 10, pp. 1395-1409, 2009. 


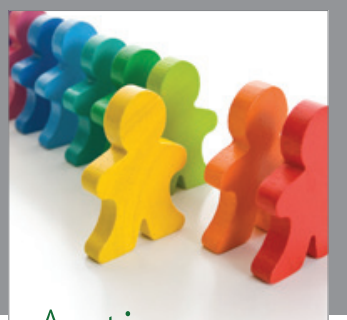

Autism

Research and Treatment
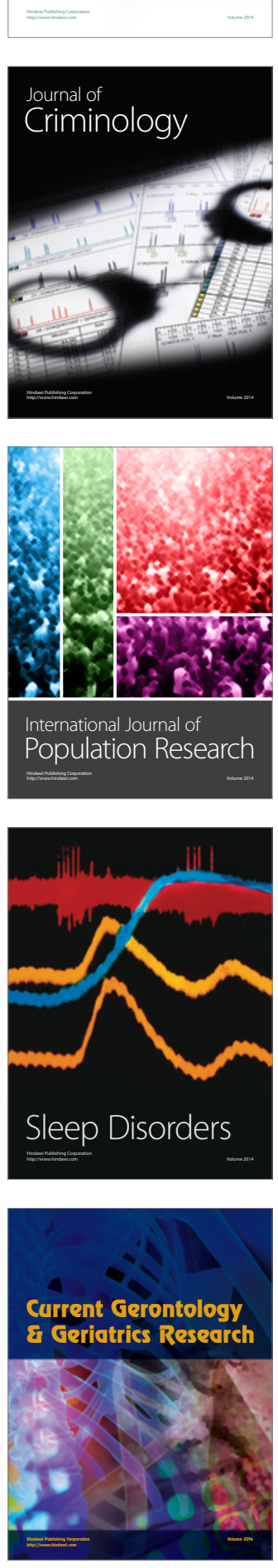
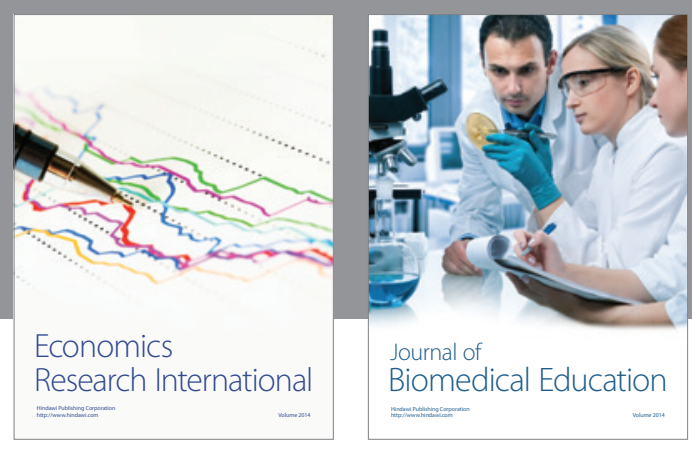

Journal of

Biomedical Education

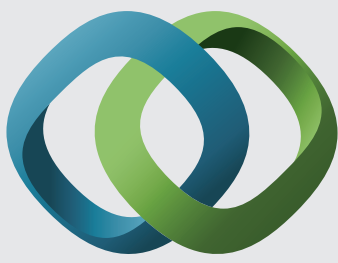

\section{Hindawi}

Submit your manuscripts at

http://www.hindawi.com
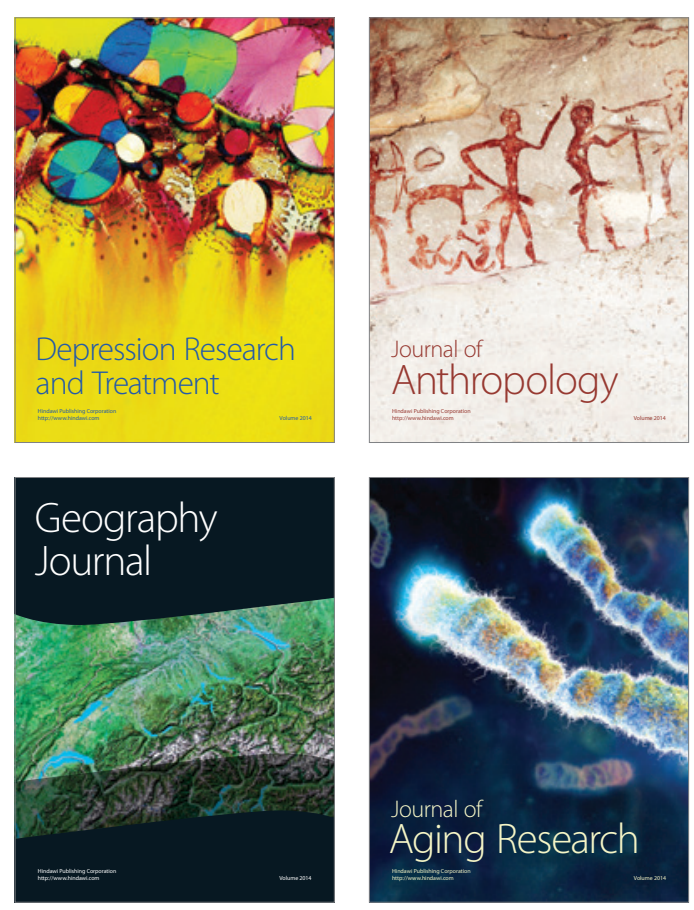

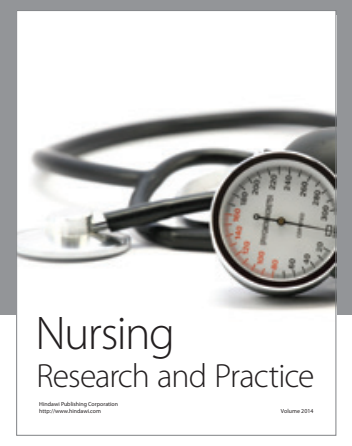

Nursing

Research and Practice

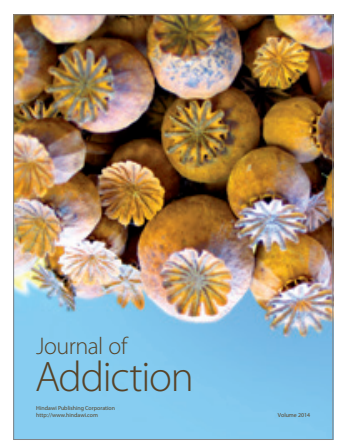

Child Development

Research

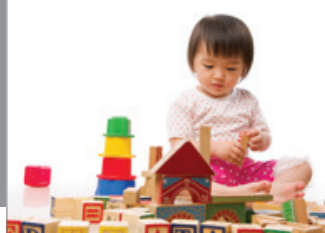

迥
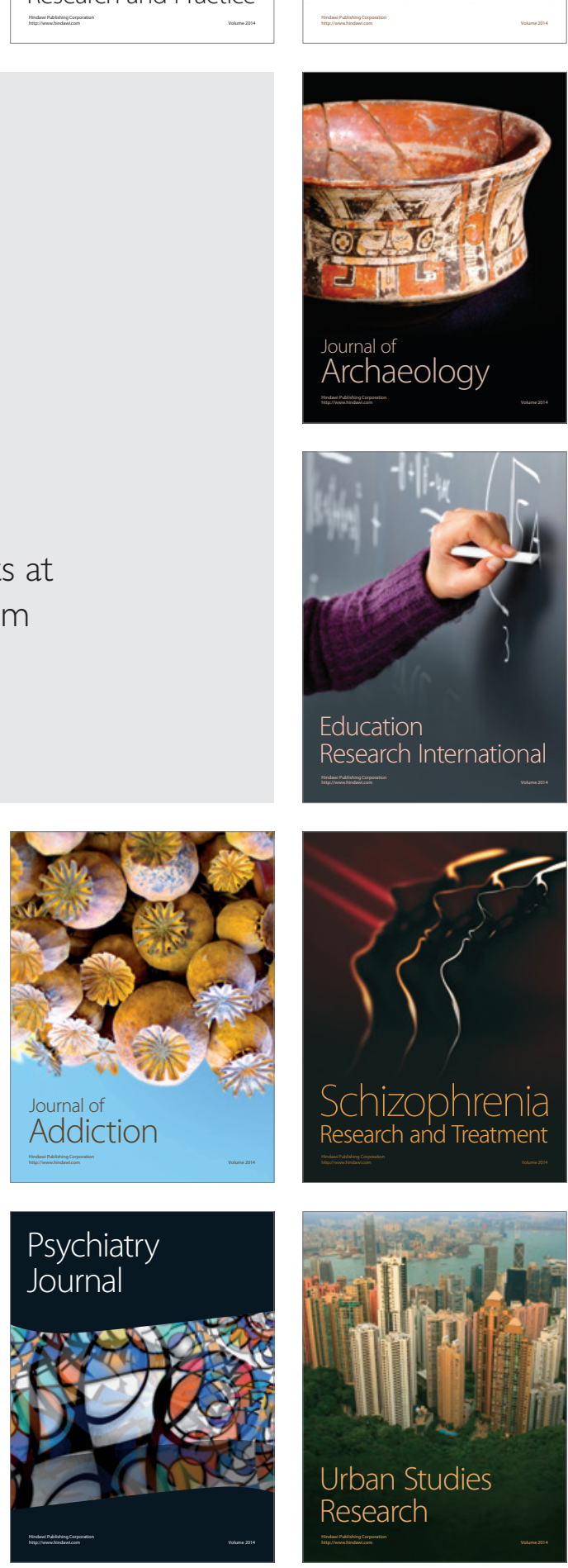